\title{
Categories and Word Formation Paraphrases of Derivatives REFERRING TO MEANS OF ACTIVITY (NINSTR): THE EXAMPLE OF BULGARIAN WORDS FORMED WITH THE $-A /$ - $Я$ SUFFIX (FIRST PART)
}

\author{
IGNACY DOLIŃSKI \\ UNIVERSITY OF WARSAW \\ i.m.dolinski@wp.pl
}

The aim of the article is to provide an overview and analysis of the conceptual framework and methodology used by Vyara Maldzhieva in the $9^{\text {th }}$ volume of Gramatyka konfrontatywna butgarsko-polska (Bulgarian-Polish Contrastive Grammar) devoted to word formation. Overall, the author (who bases his work on the same theoretical assumptions as the ones adopted in Noam Chomsky's transformational-generative grammar and the analysis of predicate-argument structure or semantic roles, cf. Charles J. Fillmore) agrees with Maldzhieva's classification. However, he suggests that the array of word formation sub-categories of Nomen Instrumenti should be broadened so as to include derivative groups which can be described via real word formation paraphrases (the Quasi-Instrument - part of the Subject's body used for a given activity, NInstr|NLoci - vessels used to perform an activity, logical Instrument - texts and gestures which can be described via word formation paraphrase, and „tool of the tool” formula expressing today's advancements in technology, closer in meaning to an impersonal agent). A more rigid construction of word formation paraphrases is proposed with unexpressed predicates (i.e., derivatives coming from nouns); the argumentation is based on an analysis of one group of Bulgarian derivatives referring to Nomen Instrumenti separated on formal grounds (feminine derivatives with the $-a /-я$ suffix).

Keywords: semantic roles, Nomen Instrumenti, word formation paraphrase

\section{REFERENCES}

Barbolova 1989: Barbolova, Z. Imena za instrumenti sas sufiks -ach v balgarskite dialekti [Nomina instrumenti with sufix -ach in the Bulgarian Dialects]. -Ezik $i$ literatura, XLIV, 3, s. 81-90.

Bogusławski 1974: Bogusławski, A. Preliminaries for Semantic-Syntactic Description of Basis Predicative Expressions with Special Reference to Polish Verbs. W: O predykacji. Materiaty Konferencji Pracowni Budowy Gramatycznej Wspótczesnego Języka Polskiego IBL PAN, Zawoja 14-16.XII.1972, red. A. Orzechowska i R. Laskowski, Wrocław, s. 39-57.

Chomsky 1982: Chomsky, N. Zarys teorii składni, tłum. I. Jakubczak, Wrocław (oryg. Acpects of the Theory of Syntax, Cambridge 1965).

Dolinski 1989: Dolinski, I. Nyakolko belezhki varhu kategoriyata Nomina Instrumenti v balgarskia ezik [Some notes on Nomina Instrumenti in the Bulgarian Language]. - In: Vtori mezhdunaroden kongres po balgaristika. Dokladi, t. 23, Mladi balgaristi. Kolokvium. Sofia, s. 109-113. 
Doliński 1990: Doliński, I. Bułgarskie i polskie nazwy środków czynności. - W: Językowe studia batkanistyczne, t. II, red. M. Korytkowska, V. Koseska-Toszewa, Warszawa, s. 21-26.

Doliński 1993: Doliński, I. Bułgarskie nazwy środków czynności (NInst) z sufiksem -tel. - W: Studia gramatyczne butgarsko-polskie, red. V. Koseska-Toszewa, M. Korytkowska, t. V-VI, Warszawa, s. 71-78.

Doliński 1999: Doliński, I. Bułgarskie nazwy środków czynności (w porównaniu z polskimi). - Prace Filologiczne, t. XLIV, s. 107-112.

Fillmore1968: Fillmore, Ch. J. The Case for Case. - In: Universals in Linguistics Theory, New York, p. 1-88.

Fillmore 1969: Fillmore, Ch. J. Types of Lexical Information, - In: Studies in Syntax and Semantics, ed. by F. Kiefer, Dortrecht, p. 109-137.

Gramatyka 1992: Gramatyka konfrontatywna butgarsko-polska, t. 5: Korytkowska M., Typy pozycji predykatowo-argumentowych, Warszawa.

Gramatyka 2009: Gramatyka konfrontatywna butgarsko-polska, t. 9: Maldjieva V., Stowotwórstwo, Warszawa.

Gramatyka - Morfologia 1984: Gramatyka współczesnego języka polskiego. Morfologia, red. R. Grzegorczykowa, R. Laskowski, H. Wróbel, Warszawa.

Grochowski 1975: Grochowski M. Środek czynności w strukturze zdania. Narzędzie, substancja, materiał. Wrocław.

Ivić 1954: Ivić, M. Značenja srpskohrvatskog instrumentala i njihov razvoj (sintaksičko- semantička studija). Beograd.

Kleszczowa 1981: Kleszczowa, K. Ograniczenia semantyczne w procesie derywacji nazw narzędzi. - Prace Naukowe Uniwersytetu Ślaskiego, nr 437. Katowice.

Kleszczowa 1975: Kleszczowa, K. Struktura semantyczna rzeczowników odczasownikowych z przyrostkiem -acz. - Poradnik Językowy, z. 10, s. 539-545.

Korytkowska 1984a: Korytkowska, M. Kategoria przypadka semantycznego (na materiale języka polskiego, bułgarskiego i serbsko-chorwackiego). - W: Studia konfrontatywne polsko-południowosłowiańskie. Wrocław, s. 11-38.

Korytkowska 1984b: Korytkowska, M. Teoria przypadków semantycznych w konfrontatywnym badaniu języka bułgarskiego i polskiego. - Studia z Filologii Polskiej i Stowiańskiej, XXII, s. 87-104.

Krasnowolski 1909: Krasnowolski, A. Systematyczna składnia języka polskiego. Warszawa.

Łoś 1904: Łoś, J. Funkcje narzędnika w języku polskim. Kraków.

Lyudskanov, Yanakiev 1968: Lyudskanov, A., M. Yanakiev. Popytka sozdania generiruiushtei modeli slovoobrazovania na osnove yazyka-posrednika pri avtomaticheskom perevode [Attempt to create a generating model of word formation based on an intermediate language for automatic translation]. - Slavianskaya filologia, X, s. 149-162.

Ordęga 1990: Ordęga, G. Propozycja opisu semantycznego czeskich verbów dicendi. - SFPS XXVI, s. 197-204.

Radeva 1987: Radeva, V. Balgarskoto slovoobrazuvane [Bulgarian word formation]. Sofia. 
Още за обхвата на словообразувателната категория nomina instrumenti (NInstr) и...

Stanisheva 1958: Stanisheva, D. Tvoritel'nyi instrumental'nyi. - V: Tvoritel'nyi padezh v slavianskikh iazykakh, red. S. Bernshtein, Moskva, s. 76-126.

Wierzbicka 1969: Wierzbicka, A, Dociekania semantyczne. Wrocław.

Ignacy Doliński

University of Warsaw

Institute of Western and Southern Slavic Studies

Krakowskie Przedmieście 26/28,

00-927 Warszawa, Poland 